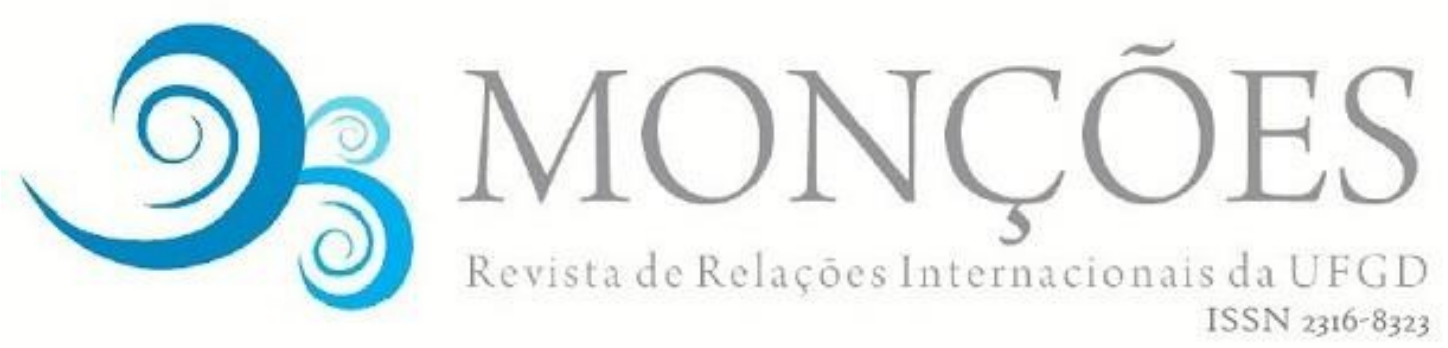

\title{
DIREITOS HUMANOS EM CHAVE DIALÓGICA: UM ENCONTRO COM A EDUCAÇÃO E O DIÁLOGO INTERCULTURAL
}

\section{VIRGINIA SANTIAGO DOS SANTOS GÓES}

Mestra em Integração Contemporânea da América Latina (PPGICAL) pela Universidade Federal da Integração Latino-americana (UNILA). Bacharela em Relações Internacionais pela FCHS - UNESP - Franca.

E-mail: virginiassgoes@gmail.com

RESUMO: O presente trabalho tem como tema central a educação em direitos humanos, objetivando debater a partir de uma perspectiva crítica, compreendendo que o mundo, em sua complexidade, é permeado por relações de poder interconectadas às microlocalidades. Visa-se, com isso, identificar possibilidades de construção dos direitos humanos no diálogo intercultural. Justifica-se a proposta apresentada pela necessidade de debate coletivo sobre os direitos humanos, tanto em seu aspecto teórico-conceitual como sua concretização na vida social. Neste sentido, a educação é identificada como locus importante para análise dos direitos humanos.

PALAVRAS-CHAVE: educação em direitos humanos; diálogo intercultural; geopolítica do conhecimento.

\section{HUMAN RIGHTS IN DIALOGIC KEY: A MEETING WITH EDUCATION AND INTERCULTURAL DIALOGUE}

\begin{abstract}
This paper focuses on human rights education, aiming to debate from a critical perspective, understanding that the world, in its complexity, is permeated by interconnected power relations with the microlocalities. It aims at identifying possibilities for the construction of human rights in intercultural dialogue. The proposal presented is justified by the need for a collective debate on human rights, both in its theoretical-conceptual aspect and its concretization in social life. In this sense, education is identified as an important locus for the analysis of human rights.
\end{abstract}

KEY WORDS: human rights education; intercultural dialogue; geopolitics of knowledge.

\section{DERECHOS HUMANOS EN CLAVE DIALÓGICA: UN ENCUENTRO CON LA EDUCACIÓN Y EL DIÁLOGO INTERCULTURAL}

RESUMEN: El presente trabajo tiene como tema central la educación en derechos humanos, 
objetivando debatir desde una perspectiva crítica, comprendiendo que el mundo, en su complejidad, está impregnado por relaciones de poder interconectadas a las microlocalidades. Se pretende, con ello, identificar posibilidades de construcción de los derechos humanos en el diálogo intercultural. Se justifica la propuesta presentada por la necesidad de debate colectivo sobre los derechos humanos, tanto en su aspecto teórico-conceptual como su concreción en la vida social. En este sentido, la educación es señalada como locus importante para el análisis de los derechos humanos.

PALABRAS CLAVE: educación em derechos humanos; diálogo intercultural; geopolítica del conocimiento.

\section{Introdução}

O presente trabalho tem como objetivo central a compreensão dos direitos humanos a partir de debates críticos às concepções clássicas ainda predominantes, tendo como conceitos norteadores o diálogo intercultural e a geopolítica do conhecimento e, como recorte analítico, a educação em direitos humanos (EDH).

A proposta surge de algumas inquietações proporcionadas por espaços acadêmicos de debate sobre direitos humanos. Pretende-se responder ao problema central presente no questionamento sobre quais perspectivas conceituais norteiam a educação em direitos humanos difundida pelas Nações Unidas e como a EDH está posicionada nos diferentes usos que se faz dos direitos humanos na esfera internacional.

Para a análise, utilizaremos uma metodologia teórico-bibliográfica, complementada pelos três primeiros itens do documento oficial do Programa Mundial de Educação em Direitos Humanos (PMEDH), elaborado pelo Alto Comissariado das Nações Unidas para os Direitos Humanos (ACNUDH) e pela Organização das Nações Unidas para a Educação, a Ciência e a Cultura (UNESCO).

Para o melhor desenvolvimento da proposta, foram elaboradas algumas seções. Na primeira, debater-se-á o âmbito conceitual dos direitos humanos, especialmente para compreender criticamente o posicionamento de perspectivas em seus respectivos contextos. Na segunda seção, analisaremos a complexidade do uso dos direitos humanos no contexto da geopolítica do conhecimento em contraste com seu potencial emancipador, e abordaremos o conceito de diálogo intercultural como chave para a construção desse potencial. Na terceira e última seção, faremos uma análise discursiva dos três primeiros itens do PMEDH de modo a identificar, em 
seus objetivos e finalidades, as potencialidades e limites desse modelo de educação em direitos humanos, tendo como panorama basilar $o$ debate abordado anteriormente.

Uma vez apresentados os objetivos, desenvolver-se-á o tema aqui proposto com base em alguns conceitos transversais, aportadores de compreensões mais profundas da realidade social, em especial quando inseridas no debate sobre direitos humanos.

Um primeiro aspecto, necessário e anterior ao debate conceitual, se refere ao destaque do lugar de enunciação desde o qual se formula uma proposta analítica, uma vez considerada a impossibilidade de retirar as vivências práticas e simbólicas que participam da formação de um sujeito e, consequentemente, de uma coletividade. Nesse sentido, ressalta-se uma enunciação identificada com o horizonte de busca por transformação das realidades desiguais ainda presentes no globo, especialmente em nosso entorno latino-americano e caribenho. As lentes através das quais se pode visualizar, analisar e (pretender) uma compreensão do complexo orbe onde estamos inseridos será, então, diferente a depender da localidade, dos conceitos utilizados, das premissas centrais e dos privilégios acessados pelos sujeitos.

\section{Debate crítico sobre a edificação dos direitos humanos em termos conceituais}

Primeiramente, faz-se prudente a identificação do Direito como discurso e linguagem, construído nas relações de poder e reflexo, então, dos mecanismos discursivos que os contextos materiais implicam. Nesse sentido, abordaremos os direitos humanos para além desse campo.

Quando pretendemos compreender um tema social, muitos caminhos analíticos se fazem possíveis, a proceder dos objetivos e intencionalidades dos sujeitos interlocutores, mas também do contexto a partir do qual se concebe uma fundamentação. Com os direitos humanos não é diferente. Além de relativos a um processo histórico-social complexo, os direitos humanos têm como elemento constituinte uma complexidade derivada tanto de suas diversas e, muitas vezes, 
antagônicas perspectivas, quanto dos usos discursivos que se faz dos mesmos nas dinâmicas sociais.

O primeiro aspecto a ser debatido quanto à complexa construção dos direitos humanos consiste na sua naturalização. Para tanto, faz-se necessário o entendimento dos direitos humanos no tempo e no espaço. Eles perpassam a construção do próprio Estado-nação, cuja perspectiva homogeneizadora o sintetiza como entidade supraindividual, supostamente diferenciado por possuir a tríade de "um território, um povo, uma língua". Como a experiência coletiva nos demonstra, esse discurso não responde à realidade plural de nossas sociedades e foi responsável por processos de violações do que hoje entendemos como direitos, seja devido às pluralidades existentes com antecedência à formação artificial dos Estados nacionais, seja pela dinâmica de oposição à diferença que as categorias modernas fundadas no binarismo fornecem.

Paralelamente, há que se ressaltar um contexto social e econômico de anseio por parte dos homens brancos e proprietários de terras por menor intervenção estatal na economia e na vida social. Contexto este de oposição ao Estado absolutista e de busca por uma estrutura social alinhada ao liberalismo em seus diversos eixos. Nesse contexto sintetizado nas bandeiras das revoluções burguesas, os direitos humanos são construídos como direitos individuais a serem protegidos das ações do Estado, como relações verticais entre este e a sociedade (CAVALCANTI, 2005). Essa perspectiva nos parece complexa, pois reflete a lógica do próprio Estado liberal, uma vez advindo de uma centralização ontológica no indivíduo para a compreensão do todo social e que serve para justificar a desigualdade (MURILLO, 2007).

Por isso, podemos falar em uma naturalização dos direitos humanos, devido a que essa visão parte de uma concepção do indivíduo como ente hermético e apartado do movimento construtivo da realidade material e simbólica. Os direitos são, assim, posicionados como inerentes à condição humana, imutáveis, universais, independentes e preexistentes à organização social. Parece-nos que a naturalização é restritiva de direitos, pois pretende um enquadramento de determinadas condições sociais e culturais como universais, ou seja, naturais a todo indivíduo. Em outras palavras, descontextualizam-se comportamentos e realidades. Nesse eterno retorno 
ao jusnaturalismo (TOSI, 2005a), há, por outro lado, o estabelecimento de um "dever ser" como já existente na realidade atual.

O segundo aspecto de nossa discussão consiste na necessidade de questionarmos o positivismo nos direitos humanos. Há, anteriormente, que se destacar a formulação do positivismo em contexto histórico, marcado por um forte cientificismo que possui seu auge entre os séculos XVIII e XIX. Fundamentado em premissas tais como neutralidade, objetividade e racionalidade, a perspectiva moderna de ciência em sua fase positivista cria categorias hermeticamente sobrepostas e "inquestionáveis" em muitos debates. A ciência, como um dos pilares do projeto moderno de sociedade, acaba, em muitas situações, por justificar e legitimar subjugações materiais e simbólicas, o que escancara intencionalidades múltiplas de seu uso.

O positivismo nos direitos humanos parte de uma concepção evolutiva linear destes últimos (FLORES, 2008). Essa linearidade concebida para o tema não está apartada dos demais ramos do conhecimento, pelo contrário, é uma das características basilares da ciência positivista, especialmente por classificar em níveis hierárquicos as coletividades, os saberes, as etnias, as sexualidades, para citar alguns aspectos.

Consequentemente, a noção de linearidade vai permear a classificação positivista dos direitos humanos em gerações, construindo um plano de fundo ordenador dos direitos desde uma perspectiva de mundo moderna, ocidental e liberal do contexto do século XVIII. Em síntese, podemos posicionar essa classificação geracional positivista da seguinte forma: $1^{\underline{a}}$ geração: direitos individuais (civis), tais como liberdade, propriedade, direitos políticos, direitos relativos ao processo penal; $2^{a}$ geração: direitos sociais, econômicos e culturais, tais como trabalho, seguridade social, educação. Existem também direitos considerados de $3^{\text {a }}$ e $4^{\mathrm{a}}$ gerações, mas não nos enfocaremos em seu debate, mesmo considerando-os de extrema importância (FLORES, 2008; TOSI, 2005b) • .

Os primeiros são comumente considerados como direitos de liberdades negativas, pois preveem um Estado mais separado do indivíduo, da vida privada, portanto, não interventor nas relações sociais. Já os segundos surgem de demandas 


\section{VIRGINIA SANTIAGO DOS SANTOS GOÉS}

de grupos sociais reivindicatórios, primeiramente por direitos relacionados ao trabalho no século XIX. Há que se destacar, como argumentam Víctor Abramovich e Christian Curtis (2001), o atrelamento, no mencionado período histórico, dos direitos sociais a uma concepção de "Direito Social" que passa a destacar o papel da desigualdade material nas relações sociais e demonstrar a hierarquia que posiciona em condições diferenciadas os sujeitos. Os direitos sociais, em síntese, exigem uma estrutura estatal que seja mais ampla, pela maior ação do Estado como promotor de direitos, o que se pode considerar como liberdades positivas (ABRAMOVICH; CURTIS, 2001; BOBBIO, 2004). Para o positivismo, as gerações são hierarquizadas, priorizando os direitos individuais. Por sua vez, os direitos sociais, econômicos e culturais, ao dependerem de recursos do Estado para sua aplicação, acabam por não ter eficácia imediata. Concebidos os direitos como interdependentes, indissociáveis para uma vida digna e autônoma dos sujeitos, percebe-se a incapacidade do positivismo em explicar e acionar sobre a vida concreta.

Por essas e outras questões, nos parece importante posicionar os direitos humanos para além do campo do Direito, uma vez que este não contempla a complexidade social. Nesse sentido, há diferentes aportes que nos auxiliam na compreensão dos direitos humanos para além do debate tradicional.

Joaquín Herrera Flores (2008) contribui ao debate ao propor uma nova definição de direitos, transgredindo o formalismo jurídico. Para o autor, "[...] más que derechos 'propiamente dichos' son procesos; es decir, el resultado, siempre provisional, de las luchas que los seres humanos ponen en práctica para poder acceder a los bienes necesarios para la vida." (2008, p. 22). Então, podemos conceber os direitos não como herméticos, fixos, e sim como movimentos, e como tais, incessantes, mais profundos do que o alcance da formalização jurídica.

Com esse debate conceitual em vista, avançaremos na análise de algumas contradições dos direitos humanos, uma vez percebidos como embrenhados de construtos discursivos.

\subsection{Direitos humanos em dubiedade: entre a opressão e a emancipação}


A descontextualização de realidades e seus comportamentos com consequente exportação ao resto do mundo é uma característica importante da formação dos direitos humanos, e como veremos mais adiante, representa um alinhamento à lógica globalizadora da configuração do mundo moderno. Este mundo moderno é aqui percebido como um modelo sistemático de aspiração centralizadora de um modo de vida e de pensamento e gestado no final do século $X V$, início do século $\mathrm{XVI}$, com a invasão e posterior colonização de territórios do que hoje se concebe como América Latina. Assim, o período comumente conceituado como modernidade do século XVIII, devido especialmente ao lluminismo e às revoluções burguesas é, segundo a perspectiva aqui apontada, uma fase interna da modernidade, uma segunda modernidade (DUSSEL, 2005).

A modernidade, como projeto local de pretensão universal, que se exporta ao resto do mundo com diferentes violências, das quais podemos citar a estrutural, a direta e a cultural (GALTUNG, 1985), se edifica em uma estrutura binária de oposição pela diferença, cujas categorias hierarquizam sujeitos, suas respectivas coletividades, suas formas de organização social, e, não menos importante, seus conhecimentos.

Com esse panorama, o conceito de geopolítica do conhecimento contribui na compreensão do mundo. Para Catherine Walsh (2004, p. 2), este conceito transcende a compreensão do espaço enquanto elemento físico, posicionando outras características formadoras das subjetividades. Ao entendermos 0 conhecimento como construto de uma realidade própria, passa-se a identificá-lo em um contexto, e, portanto, permeado de intencionalidades e de poder. (LOOMBA, 1998).

Hablar de las geopolíticas del conocimiento, entonces, es reconocer la naturaleza hegemónica de la (re)producción, la difusión y el uso del conocimiento, no simplemente como ejercicio académico, sino como parte fundamental del sistema-mundo capitalista y moderno, que a la vez y todavía, es colonial. (WALSH, 2004, p. 3)

Este quadro perspectivo se faz importante em nossa análise, pois localizamos a edificação do eurocentrismo em tempo e espaço, contextualizando segundo as relações de poder existentes. Os direitos humanos, então, passam a ser identificados como construto de uma realidade social muito específica e do contexto da segunda modernidade. Por isso, como vimos na seção anterior, os direitos 


\section{VIRGINIA SANTIAGO DOS SANTOS GOÉS}

humanos são construídos discursivamente no bojo do liberalismo, com defesa da menor intervenção do Estado na vida privada.

Boaventura de Sousa Santos, ao construir uma análise dos direitos humanos desde um olhar multicultural, fornece dois conceitos que consideramos pertinentes para a construção analítica aqui pretendida: localismo globalizado e globalismo localizado. O primeiro "consiste no processo pelo qual determinado fenômeno local é globalizado com sucesso [...]" (SANTOS, 1997, p. 16). Já o segundo, "consiste no impacto específico de práticas e imperativos transnacionais nas condições locais, as quais são, por essa via, desestruturadas e reestruturadas de modo a responder a esses imperativos transnacionais" (SANTOS, 1997, p. 16).

Os direitos humanos se enquadram na proposta analítica de Boaventura, pois são formulados em uma localidade e exportados ao globo como universais. Podem, então, ser consideramos como um localismo globalizado, pois se constroem desde o mundo ocidental mas são discursivamente propagados a outras localidades. Esse processo de exportação dos direitos humanos possui, nesse sentido, um caráter de imposição epistemológica e cultural quanto às concepções do que são direitos humanos, suas categorias, o sentido de humanidade que carregam, entre outros aspectos. Muitas vezes utilizados como justificativa discursiva para alcance de objetivos políticos e econômicos no cenário internacional, com violações dos mesmos direitos existentes no âmbito simbólico. Enfim, os direitos humanos se manifestam como um "imperialismo moral" (SEGATO, 2007) quando utilizados como instrumento de apelo discursivo nas relações de poder.

Por outro lado, há que se ressaltar a potencialidade emancipadora que os direitos humanos possuem para exposição de violações, não meramente em aspecto jurídico, mas como instrumento de luta de sujeitos e coletividades ao redor do globo. Sua construção mais plural vai sendo realizada desde localidades diversas, especialmente em contextos de intensa desigualdade de oportunidades.

A potencialidade emancipadora dos direitos humanos existe precisamente quando diferentes concepções e culturas passam a ser consideradas na formulação de pautas e estratégias. Para tanto, formas outras de definir os direitos humanos devem ser valorizadas. Por esse ângulo, Boaventura de Sousa Santos defende 
diálogos interculturais como caminho "[...] para a definição de valores ou exigências máximos e não por critérios mínimos da definição da dignidade humana e dos direitos [...]" (SANTOS, 2003, p. 55). Isso questiona a ideia de mínimo aceitável para a vida digna e aponta a reivindicação por direitos como um movimento com horizonte a ser alcançado coletivamente.

\begin{abstract}
É a partir destas condições que se abre o espaço para uma concepção dos direitos humanos que, em vez de postular um (falso) universalismo, assenta numa constelação de ideias distintas de dignidade humana, tornadas mutuamente inteligíveis e mutuamente capacitantes através de um diálogo intercultural. (SANTOS, 2003, p. 55-56).
\end{abstract}

Esse diálogo intercultural, há que se ressaltar, não idealiza as relações sociais em um discurso raso, mas identifica o posicionamento desigual das culturas na dinâmica de poder internacional devido à concentração da narrativa histórica por certas coletividades.

Como também afirma Santos, "[...] é preciso criar inteligibilidade sem destruir a diversidade" (2007, p. 39-40). O campo dos direitos humanos se apresenta com condições próprias e necessárias para essa inteligibilidade diversa. Em um contexto de disputa discursiva entre perspectivas diferentes sobre direitos humanos, nos parece relevante para a luta por transformação de nossas realidades a ferramenta de tradução, sendo esta "[...] um processo intercultural, intersocial. [...] é traduzir saberes de outros saberes, traduzir práticas e sujeitos de uns aos outros, é buscar inteligibilidade sem 'canibalização', sem homogeneização." (SANTOS, 2007, p. 3940).

A construção do diálogo intercultural e tradutor de direitos humanos se faz essencial para a modificação das estruturas de poder e pode, inclusive, servir, como se tem observado em certos posicionamentos institucionais, para fortalecer a proteção dos direitos humanos. Mesmo quando se analisa a formação de instituições de proteção dos direitos humanos, com todas as críticas pertinentes e necessárias, especialmente quando verificamos as debilidades para o cumprimento de sentenças no sistema internacional, há que se admitir que essas instâncias representam uma possibilidade de recurso, muitas vezes em situações de extrema vulnerabilidade, quando de uma violação sofrida. Quando aliadas a uma visão intercultural, essas instâncias representam espaços de pressão internacional e espelho para lutas travadas em outros meios cotidianos. Há que se transcender 
esses mecanismos e pensar a potencialidade emancipadora que os direitos humanos possuem quando construídos desde a pluralidade das vivências e epistemologias.

Em síntese, o posicionamento crítico e intercultural na luta por direitos humanos é aqui defendido como possibilitador de resistência às diferentes manifestações e faces que a violência possui. Partir dessa perspectiva aponta a passos desafiadores, mas, sem dúvida, transformadores para nossas lutas e resistências desde localidades do "Sul" global. Quando os direitos humanos são pensados mais como um processo do que como algo fechado, hermético e imutável, tem-se a possibilidade de construção desde diversas realidades e visões de mundo.

\subsection{Educação em direitos humanos (EDH) desde uma mirada dialógica}

Entende-se que a construção dos organismos internacionais é fruto de contextos mundiais específicos e cujos objetivos respondem a uma dinâmica de correlação de forças muito desigual em âmbito internacional. Há organismos, como - Banco Mundial (BM) e o Fundo Monetário Internacional (FMI) que, em seus delineamentos e manuais implementados nos países, fomentam o acirramento das condições de dependência, especialmente quando analisados os discursos e políticas direcionados aos chamados países do "Terceiro Mundo", ou "subdesenvolvidos" - nomenclaturas questionáveis, tendo em vista seu caráter categorial e etapista. Tais organismos, então, representam uma pauta econômica neoliberal de forte ingerência nos processos internos, moldando áreas da educação, por exemplo. (YATIM; MASO, 2014).

Nesse sentido, a Organização das Nações Unidas também é compreendida, neste trabalho, em sua complexidade, por sua construção ocidental e sua instrumentalização em certas conjunturas globais, a depender dos interesses dos atores, suas forças, das disputas e, não menos importante, do poder simbólico na comunidade internacional. Como analisamos, a geopolítica também possui sua face epistêmica, a qual permeia a configuração do sistema internacional e, muito fortemente, dos valores construídos e defendidos no mesmo. Os organismos internacionais não escapam a essa lógica, pelo contrário, são influenciados pela 
mesma. No entanto, como anteriormente debatido, os direitos humanos, com sua dupla face (de opressão e de emancipação), devem ser concebidos com cautela, mas sem perder de vista as potencialidades que carregam, quando (e isso é essencial em nossa análise), construídos de diálogos interculturais.

Feita essa ressalva chave, há, então, a importância da elaboração, pela comunidade internacional, de instrumentos como o Programa Mundial para Educação em Direitos Humanos (PMEDH), formulado posteriormente à Década das Nações Unidas para a Educação em Matéria de Direitos Humanos (1995-2004). O PMEDH é proclamado pela Assembleia Geral da ONU em 10 de dezembro de 2004, "[...] com o objetivo de promover a implementação de programas de educação em direitos humanos em todos os setores" (ONU, 2004).

O Programa entra em vigor em 2005, quando aprovado o Plano de Ação da primeira fase, referente ao período de 2005-2007, pela supracitada Assembleia Geral (ONU, 2005), e é publicado em 2006 pela Organização das Nações Unidas para a Educação, a Ciência e a Cultura (UNESCO) e pelo Alto Comissariado das Nações Unidas para os Direitos Humanos (ACNUDH).

A seguir, pretendemos analisar especialmente os três primeiros itens do programa: A) Contexto e definição da educação em direitos humanos; B) Objetivos do Programa Mundial para Educação em Direitos Humanos; e C) Princípios condutores das atividades de educação em direitos humanos. O objetivo é compreender os elementos discursivos presentes no PMEDH que demonstrem a existência ou não de tentativas de diálogos interculturais em sua elaboração conceitual.

O programa parte de uma definição específica de educação em direitos humanos (EDH), considerando-a como

[...] um conjunto de atividades de educação, de capacitação e de difusão de informação, orientado para a criação de uma cultura universal de direitos humanos, mediante a transmissão de conhecimentos, o ensino de técnicas e a formação de atitudes. (UNESCO; ACNUDH, 2012, p. 14).

Neste espaço, percebe-se a continuidade da ideia de universalidade dos direitos humanos, mas já modificada em certa medida, uma vez percebida não como um dado natural, mas como um horizonte. 
As finalidades do PMEDH seriam:

(a) fortalecer o respeito aos direitos humanos e às liberdades fundamentais;

(b) desenvolver plenamente a personalidade humana e o sentido da dignidade do ser humano;

(c) promover a compreensão, a tolerância, a igualdade entre os sexos e a amizade entre todas as nações, os povos indígenas e os grupos raciais, nacionais, étnicos, religiosos e linguísticos;

(d) facilitar a participação efetiva de todas as pessoas em uma sociedade livre e democrática na qual impere o Estado de Direito;

(e) fomentar e manter a paz;

(f) promover um desenvolvimento sustentável centrado nas pessoas e na justiça social. (UNESCO; ACNUDH, 2012, p. 14).

Analisemos com mais detalhe algumas das mencionadas finalidades. Os pontos $a$ e $b$ remetem ao debate mais clássico de direitos humanos, cujos conceitos de liberdades fundamentais e de dignidade humana utilizados pelas organizações internacionais ainda têm incorporado poucas perspectivas mais plurais sobre a construção cultural e epistêmica das ideias que permeiam os direitos humanos.

A promoção do respeito e da tolerância à diferença presente no ponto $c$ é chave no debate aqui proposto, pois revela a importância dada ao tema na EDH. No entanto, há que se ressaltar que não está colocada transversalmente no programa mundial, ou seja, é uma finalidade central, mas não um plano de fundo que influencie as próprias concepções dos direitos humanos utilizadas.

O item $d$, por sua vez, revela a face mais política das finalidades, cujos valores verificam-se como fortemente relacionados às concepções ocidentais de direitos civis e políticos e do Direito como orientador da institucionalidade democrática do Estado.

A paz encontra-se posicionada no item e de forma pouco aprofundada, deixando questionamentos possíveis quanto à concepção de paz utilizada como premissa. Não nos adentraremos nesse debate, mas pontuamos a complexidade do tema, uma vez a paz considerada como polissêmica, com sentidos diversos em cada realidade.

Por fim, o item $f$ posiciona o desenvolvimento sustentável, tema polêmico na contemporaneidade, e cujas nuances formam um emaranhado de possibilidades de compreensão. Ao centrar as pessoas e a justiça social, a ideia de desenvolvimento é, dessa forma, menos ortodoxa e mais relacionada a uma distribuição equitativa entre os sujeitos. No entanto, há que se ressaltar a existência de perspectivas 
questionadoras da ideia de desenvolvimento, mesmo que sustentável, quando não posiciona a convivência plena entre humanidade e natureza, esta considerada como sujeito de direitos (ACOSTA, 2015; SIMBAÑA, 2011).

Os principais objetivos do PMEDH podem ser sintetizados em:

[...] promover o entendimento comum dos princípios e das metodologias básicos da educação em direitos humanos, proporcionar um marco concreto para a ação, e reforçar as oportunidades de cooperação e de associação, desde o nível internacional até o nível das comunidades. (UNESCO; ACNUDH, 2012, p. 4)

Destacamos a consideração do nível comunitário como importante na implementação da EDH. Esse aspecto é majoritariamente inferiorizado nas práticas internacionais, uma vez predominante o posicionamento estadocêntrico quanto aos atores.

Quanto às atividades educativas em matéria de direitos humanos, o programa declara nove objetivos específicos (UNESCO; ACNUDH, 2012, p. 16). Destacamos alguns conceitos e ideias atribuidores de sentido em nossa análise.

Verificam-se, em primeiro lugar, os conceitos de interdependência e indivisibilidade dos direitos humanos, rompendo, de certa forma, com a concepção geracional e desvelando a impossibilidade de conceber-se qualquer direito quando há profunda desigualdade de condições materiais e simbólicas entre os sujeitos. A pobreza, os conflitos e a discriminação são posicionados conjuntamente, e necessitários de análises pela EDH.

O fomento e a valorização das diferenças e o combate à discriminação novamente são apontados como essenciais na construção da pauta educativa, e, mais do que isso, é mencionada a centralidade de conceder meios para que as comunidades e seus sujeitos determinem "[...] suas necessidades em matéria de direitos humanos" (UNESCO; ACNUDH, 2012, p. 16). Paralelamente, aponta também o objetivo das atividades educativas inspirarem-se "[...] nos princípios de direitos humanos consagrados nos diferentes contextos culturais e levar em conta os acontecimentos históricos e sociais de cada país". Esse nos parece um posicionamento destacável, pois manifesta certa intencionalidade na construção autônoma das pautas em direitos humanos desde as particularidades. Sabe-se da ainda prevalecente concepção ocidental, especialmente liberal, dos direitos humanos no sistema internacional, reflexo de sua construção desde um contexto 


\section{VIRGINIA SANTIAGO DOS SANTOS GOÉS}

histórico e cultural específico e a recorrente apropriação discursiva por atores internacionais. No entanto, em termos simbólicos, a menção às particularidades representa ao menos um passo no caminho do diálogo intercultural nos direitos humanos.

Quanto a esforços nacionais de formulação específica sobre EDH, alguns países desenvolveram, com especificidade, planos de ação ou estratégias. Dentre eles, Brasil, Burundi, Colômbia, Costa Rica, Croácia, Eslováquia, Fiji, Filipinas, França, Grécia, Honduras, Japão, Jordânia, Níger, Peru, Portugal, República Dominicana, Senegal, Turquia e Uruguai. Outros também mencionam a EDH em programas mais gerais sobre direitos humanos. (UNESCO, online). Contudo, esses esforços parecem ainda não representar um aprofundamento dos objetivos traçados, especialmente pela dificuldade de superar as barreiras institucionais e de alcançar as múltiplas realidades internas. Quando pensamos na realidade latino-americana, por exemplo, segundo análises de dados contidas no Informe Interamericano sobre Educação em Direitos Humanos, "[...] la mayoría de las políticas existentes son todavía muy generales, dispersas y, en algunos casos, ambiguas" (INSTITUTO INTERAMERICANO DE DERECHOS HUMANOS, 2011, p. 10).

Por sua vez, o diálogo intercultural passou a ter mais relevância nos espaços da UNESCO ao longo dos últimos anos. E pode-se perceber uma tentativa crescente de busca por escuta e compilação de conceitos dinâmicos e próprios aos países membros. Apesar de ainda incipiente em âmbito institucional, esse não é um debate novo, especialmente entre intelectuais e ativistas comunitários de regiões como a América Latina e o Caribe. Os esforços da UNESCO para aprofundamento do tema pode ser visualizado em dados como os publicados na pesquisa sobre diálogo intercultural de 2017. A pesquisa foi respondida por 43 Estados membros, e os resultados apontam a importância do diálogo intercultural para objetivos relevantes. Os direitos humanos se destacam na pesquisa: $98 \%$ das respostas destacam a contribuição do diálogo intercultural para reforçar o respeito aos direitos humanos (UNESCO, 2018, p. 19) e 73\% reconhecem o seu potencial transformador para alcance dos direitos humanos (UNESCO, 2018, p. 20).

Por fim, ao considerarmos a educação como locus de potencialidades para modificação de posturas individuais e coletivas, percebe-se um escopo importante de relação entre esta, os direitos humanos e o diálogo intercultural. Há, no entanto, 
uma defasagem na construção de políticas efetivas em âmbito estatal, das quais se demanda aprofundamento estratégico de médio e longo prazos, que transcendam a característica meramente discursiva e diagnóstica. A transposição da fase atual dos três eixos aqui expostos, ainda pouco debatidos conjuntamente em termos de planificação, para uma etapa de ação em nível micro, compatível com as múltiplas realidades culturais internas aos Estados, pode representar um caminho para consolidação das proposições internacionais sobre o tema em diálogo com as concepções comunitárias próprias.

\section{Considerações finais}

"[...] as pessoas e os grupos sociais têm o direito a ser iguais quando a diferença os inferioriza, e o direito a ser diferentes quando a igualdade os descaracteriza" (SANTOS, 2003, p. 56).

Podemos conceber, com base na análise realizada, algumas potencialidades do Programa Mundial de Educação em Direitos Humanos, tais como: i) a representação de um caminho mais interlocutor entre diversas realidades para construção de mecanismos mundiais; ii) a concepção de indissociabilidade entre os diversos direitos, o que pode favorecer interrogações positivas nos debates sobre garantia de direitos em âmbito interno; iii) o fomento a práticas e métodos pedagógicos participativos e formulados com criticidade; iv) a importância para modificação do imaginário social; v) o posicionamento do nível comunitário como importante no cenário internacional, e não como mero receptor de políticas.

Em contrapartida, alguns limites, não apenas do PMEDH, mas da educação em direitos humanos em geral, merecem menção, tais quais: i) a dificuldade de implementação, mesmo quando da existência de planos nacionais elaborados com base nos objetivos do PMEDH, devido às modificações de perspectivas políticas internas nos poderes institucionais; ii) a impossibilidade de implementar a educação em direitos humanos se desconsideradas as desigualdades de oportunidades dos sujeitos no ambiente escolar, onde as condições mínimas para aprendizagem inexistem; iii) a educação em direitos humanos não pode ser restrita a debates específicos e generalistas, precisa ser transversal e estar alinhada à luta pela 
transformação profunda do sistema educativo como um todo.

É necessário, então, pensarmos na educação em direitos humanos aliada a uma educação com direitos humanos e interconectada às lutas por transformação social de nossas localidades.

Como afirma Paulo Freire, "na medida em que a condição básica para a conscientização é que seu agente seja um sujeito, isto é, um ser consciente, a conscientização, como a educação, é um processo específica e exclusivamente humano." (1981, p. 53). •

É nesse sentido que a educação em direitos humanos tem a potencialidade, quando elaborada em diálogos interculturais, de ser um processo de conscientização do educador e do educando como sujeitos. Porque "enquanto o ser que simplesmente vive não é capaz de refletir sobre si mesmo e saber-se vivendo no mundo, o sujeito existente reflete sobre sua vida, no domínio mesmo da existência e se pergunta em torno de suas relações com o mundo." (FREIRE, 1981, p. 53).

A educação não reside apenas em um bem pelo qual se deve lutar, ou, por outro lado, em apenas um meio para exercício de valores como direitos humanos. Esses dois eixos devem ser compreendidos como intrínsecos e indissociáveis no exercício de direitos. Ela representa, então, ponto chave para fortalecimento das lutas por transformação social. Assim sendo, a educação em direitos humanos deve estar alinhada à luta por combate às desigualdades de oportunidades intrínsecas ao sistema, para construir-se efetivamente como prática da liberdade (FREIRE, 1967) não apenas como elemento do indivíduo, mas em sua concepção coletiva e comunitária.

\section{Referências}

ABRAMOVICH, Víctor; CURTIS, Christian. Los derechos sociales en el debate democrático. Cuadernos electrónicos de filosofía del derecho, n. 4, p. 37-72, 2001.

ACOSTA, Alberto. El Buen Vivir como alternativa al desarrollo: algunas reflexiones económicas y no tan económicas. Política y Sociedad, v. 52, n. 2, p. 299-330, 2015.

BOBBIO, Norberto. A era dos direitos. Rio de Janeiro: Elsevier, 2004. 
CAVALCANTI, Carlos André. História moderna dos direitos humanos: uma noção em construção. In: TOSI, Giuseppe. (org.). Direitos humanos: história, teoria e prática. João Pessoa: Editora Universitária/UFPB, 2005. p. 57-95.

DUSSEL, Enrique. Europa, modernidade e eurocentrismo. In: LANDER, Edgardo. (org.). A colonialidade do saber: eurocentrismo e ciências sociais. Perspectivas latino-americanas. Buenos Aires: CLACSO, 2005. p. 24-32.

FLORES, Joaquín Herrera. La reinvención de los derechos humanos. Andalucia: Atrapasuenos, 2008.

FREIRE, Paulo. Educação como prática da liberdade. Rio de Janeiro: Paz e Terra, 1967.

FREIRE, Paulo. Ação cultural para a liberdade. 5. ed. Rio de Janeiro: Paz e Terra, 1981.

GALTUNG, Johan. Sobre la paz. Barcelona: Fontamara, 1985.

INSTITUTO INTERAMERICANO DE DERECHOS HUMANOS. Informe interamericano de la educación en derechos humanos. San José: IIDH, 2011.

LOOMBA, Ania. Colonialism/postcolonialism. London; New York: Routledge, 1998.

MURILLO, Susana. Produção de pobreza e construção de subjetividade. In: CIMADAMORE, Alberto D.; CATTANI, Anronio David (org.). Produção de pobreza e desigualdade na América Latina. Porto Alegre: Tomo Editorial/ CLACSO, 2007. p. 39-78.

ONU, Assembleia Geral das Nações Unidas. Resolução $n^{\circ}$ 59/113-A. Programa Mundial para Educação em Direitos Humanos. Disponível em: $<$ http://unesdoc.unesco.org/images/0014/001478/147853por.pdf>. Acesso em: 10 maio. 2017.

ONU, Assembleia Geral das Nações Unidas. Resolução $n^{\circ}$ 59/113-B. Programa Mundial para Educação em Direitos Humanos. Disponível em: $<$ http://unesdoc.unesco.org/images/0014/001478/147853por.pdf>. Acesso em: 10 maio. 2017.

SANTOS, Boaventura de Sousa. Por uma concepção multicultural dos direitos humanos. Revista Crítica de Ciências Sociais, n. 48, p. 11-32, 1997.

SANTOS, Boaventura de Sousa. Introdução: para ampliar o cânone do reconhecimento, da diferença e da igualdade. In: Reconhecer para libertar: os 
caminhos do cosmopolitismo multicultural. Rio de Janeiro: Civilização Brasileira, 2003. p. 25-68.

SANTOS, Boaventura de Sousa. Renovar a teoria crítica e reinventar a emancipação social. São Paulo: Boitempo, 2007.

SEGATO, Rita Laura. Intoducción: políticas de la identidad, diferencia y formaciones nacionales de alteridad. In: . La Nación y sus otros: raza, etnicidad y diversidad religiosa en tiempos de políticas de la identidad. Buenos Aires: Prometeo Libros, 2007. p. 15-36.

SIMBAÑA, Floresmillo. El Sumak Kawsay como proyecto político. In: LANG, Miriam; MOKRANI, Dunia (orgs.). Más allá del desarrollo. Quito: Abya Ayala, 2011. p. 219226.

TOSI, Giuseppe. História conceitual dos direitos humanos. In: TOSI, Giuseppe (org.). Direitos humanos: história, teoria e prática. João Pessoa: Editora Universitária/UFPB, 2005a. p. 128-163.

TOSI, Giuseppe. Direitos humanos: reflexões iniciais. In: TOSI, Giuseppe (org.). Direitos humanos: história, teoria e prática. João Pessoa: Editora Universitária/UFPB, 2005b. p. 21-55.

UNESCO; ACNUDH. Plano de ação. Programa mundial para educação em direitos humanos: primeira fase. Brasília: UNESCO/ Alto Comissariado das Nações Unidas para os Direitos Humanos, 2012.

UNESCO. National action plans for human rights education. Acesso em: 30 set 2018. Disponível em:

$<$ https://www.ohchr.org/EN/Issues/Education/Training/Pages/NationalActionPlansHu manRightsEducation.aspx>.

UNESCO. UNESCO survey on intercultural dialogue 2017: analysis of findings. Paris: UNESCO, $2018 . \quad$ Disponível em: $<$ http://uis.unesco.org/sites/default/files/documents/unesco-survey-interculturaldialogue-2017-analysis-findings-2018-en.pdf>.

WALSH, Catherine. Geopolíticas del conocimiento, interculturalidad $y$ descolonialización. Disponível em: <http:/icci.nativeweb.org/boletin/60/walsh.html>. Acesso em: 22 maio 2017. 
YATIM, Leila; MASO, Tchella. Banco Mundial e geopolítica do conhecimento: a privatização do ensino superior. Revista Educação, Cultura e Sociedade, Sinop, v. 4, n. 1 (Ed. Esp.), p. 80-94, 2014.

Recebido em: 04/04/2018

Aprovado em: 02/10/2018 